\title{
Children's Agency, Interests, and Medical Consent
}

\author{
Jennifer Baker
}

Published online: 20 October 2013

(C) Springer Science+Business Media Dordrecht 2013

\begin{abstract}
In this paper I argue that reference to a developmental account of agency can help explain, and in cases also alter, our current practices when it comes to the non-consensual medical treatment of children. It does this through its explanation of how stages of development impact the types of interests we have.
\end{abstract}

Keywords Consent - Minors · Mature minor doctrine $\cdot$ Narrative self-constitution

\section{Introduction}

Classic summaries of our legal and medical tradition hold that "Every human being of adult years and sound mind has a right to determine what shall be done with his own body; and a surgeon who performs an operation without his patient's consent commits an assault" (Schloendorff v. Society of New York Hospital 1914). "Consent" certainly receives due attention in the Bioethics literature. "Sound mind" is a regularly contested notion, as the public is aware. The qualifier "adult," however, can go unnoticed. Yet this really won't do. Very young children are held down when given shots. Children who resist procedures, even routine dental cleanings, are commonly sedated. There is a bright line between how we treat adults and how we treat children. We should figure out how to provide it with justification.

If we have not yet done this, and I'll argue we have not, it is likely due to how we take the difference between childhood and adulthood to be self-evident. Yet if we look to practice, we see very little to support that idea. Before the concept of a "mature minor" was reflected in various court decisions and several states' laws, clinicians found something unconscionable about undertaking a medical procedure

\footnotetext{
J. Baker $(\bowtie)$

Philosophy Department, College of Charleston, Charleston, SC 29424, USA

e-mail: BakerJA@cofc.edu
} 
on a dissenting teenager. Now, in South Carolina, when a person has reached the age of 16 she may give formal, legal, consent to medical treatment, barring a refusal to undergo an operation that is considered life-saving. ${ }^{1}$ New Mexico allows for minors who can display that they "understand the nature of that unemancipated minor's medical condition, the risks and benefits of treatment and the contemplated decision to withhold or withdraw life-sustaining treatment," to refuse even lifesustaining treatment. ${ }^{2}$ Other states have developed other ways to address this issue. Tennessee's Supreme Court has made use of the idea that until age seven a child has no capacity to consent, between seven and fourteen she is taken to have a "rebuttable presumption" of having no capacity to consent. And from fourteen until legal adulthood she is granted a "rebuttal presumption" of capacity to consent (Mature Minor Doctrine, TN). Federal law specifies that minors facing sexual health issues have the power to grant medical consent, and state laws recognize that homeless minors and minors with mental or addiction issues may consent to treatment (Hartman 2002). When it comes to participation in research, the notion that we must seek "affirmative agreement" from minors has been proposed (American Academy of Pediatrics Committee on Bioethics 1995). Clinicians are to seek "assent" from minor patients when possible. This involves the patient being made aware of her condition and being told what to expect with any course of treatment. Whether the patient displays understanding of these matters, and whether she is subject to any outside pressures are to be considered. After that, the minor patient's willingness to accept the treatment can be solicited. This type of "assent" is not taken to be as informed as an adult's "consent," however. And bioethicists disagree on not only whether there should be an age associated with the ability to give assent but also on what might make such "assent" valid (Lee et al. 2006).

The issues that underlie a child's inability to meaningfully consent to medical treatment are analyzed, in court opinions and bioethicists' articles, in terms of concepts like these: experience and judgment, best interests, an open future, flourishing, dignity, conflicts of interests, and the liberty and privacy rights of parents. Sometimes a large set of concepts serve some common purpose. For example, rich and varied descriptions of human or patient rights may function by directing policy toward respect for (as an example) a patient's autonomy. Unlike this, is common to find authors "balancing" the concepts I've listed against each other. The concepts I've listed are also often used alongside each other by authors recommending opposed policies. This means the courses of action they are associated with cannot be predicted.

In addition, when sources that are regarded as authorities on bioethics use these concepts, the impression given, to clinicians and parents, can be that an ethical matter is settled. In the case of appropriate medical care for children and other nonautonomous agents, this needlessly obscures and limits available options. If we consider what has been done philosophically to defend our practice of denying

\footnotetext{
${ }^{1}$ S.C.Code Ann. § 63-5-340 (2010); Kozup v. Georgetown Univ., 851 F.2d 437, 439 (D.C.Cir.1988); People v. E.G., 549 N.E.2d 322, 325 (Ill.1989); Younts v. St. Francis Hosp. \& Sch. of Nursing, 469 P.2d 330, 338 (Kan.1970); In re Swan, 569 A.2d 1202, 1205 (Me.1990); In re Rena, 705 N.E.2d 1155, 1157 (Mass.App.Ct.1999).

${ }^{2}$ N.M. Stat. Ann. § 24-7A-6.1.C. (1997).
} 
children consent, minor variations in the approaches do not alter the fact that we have gotten little further than this: the inability of minors to grant consent is a matter of children lacking the appropriate "experience" and "judgment."

Parental rights have occupied far more of our focus. Yet even when states proclaim parental rights must be as "unfettered" as possible, courts have determined that a child's interests can trump parental rights. A child's presumed interest in survival trumps parent rights, for example. This means that despite how thoroughly defended the notion of parental rights is, children's interests remain in play. And children's interests cannot be determined through some method of what is left when parents' rights have been exhausted.

There are times when a shared, stated rationale for anything may be unnecessary. Efforts are regularly taken, and improvised, to address the health care needs of children in a variety of circumstances, absent any explanation of what a minor's homelessness, addiction, sexual health, or mental illness share in common. Hospitals, courts, religions and parents find means of negotiating with nothing like any settled philosophical take. Needless dental operations on children would be counted as assault on any number of explanations of why minors cannot consent to medical treatment (Neiman Reports 2013). Good practice does not always require theory.

Yet in this paper, I would like to show that we can readily make practical use of more explanation of the status of children in certain types of deliberations concerning their medical care. In particular, further explanation could alter treatment of children with severe cognitive disabilities as well as those who are born intersex. Issues of agency are crucial to how we ought to recognize and respond to children's interests. The concepts that currently stand in for the interests of children, however, fail to represent children's agency and mask its relevance.

\section{Consent}

Gaining consent to a course of medical treatment fulfills a number of purposes. It acknowledges that the patient retains rights over her own person. It confers a certain authority to the course of treatment about to be delivered. And it allows a patient to decline a course of treatment, even if this would risk harm. We do not "grant" that adults have autonomy because we are assured they will always make the most prudent decisions. Recognizing autonomy is a matter of recognizing that patients have a right to refuse even what we deem necessary for their health or survival. Our tradition maintains that autonomous adults can decline treatment without having "sensible beliefs, valid thoughts, reasonable emotions" (President \& Directors of Georgetown College Inc. 1964). ${ }^{3}$ Even foolish ideas and absurdities in reasoning are permitted. An adult's autonomy is not based on the quality or outcome of her reasoning.

\footnotetext{
${ }^{3}$ W. Burger dissent President \& Directors of Georgetown College Inc. 331 F.2d 1000 (1964). This can even be said to apply to the reasoning that adults may use when making medical decisions for their children, according to many state's laws.
} 
Of course the reasoning of a child might also be said to be insensible, invalid, under-formed, or unreasonable. These descriptors do not distinguish a child's reasoning from reasoning that of adults. Children and adolescents (ages 14-18) are often said to lack the "experience" and "judgment" that adults have. Is this what makes the difference? Is it that they lack the experience to properly understand the course of their treatment and benefits of medical care? "Experience" is not used as a criterion for adults. Adults who lack experience are not prevented from granting medical consent. ${ }^{4}$ Adults who are given conservators meet a checklist of criteria about abilities ("cannot care for self outside of home," "cannot wash self") that do not track experience.

As to differences in judgment, we can compare the status of children to adults whose situations render them temporarily unable to grant consent. Our current regulatory structure regards as appropriate some nonconsensual treatment of the mentally ill, for example. The two-part rationale is that in order to preserve a patient's best interests and to restore the patient's autonomy some treatment must be given. The patient's interests are determined through consultation with a legal guardian or family representative, and either may be asked to follow the wishes of the person as she might have made them in a better mental condition. Could we regard children in the same way? Do we determine what their interests would be if they were in some other condition? Do we imagine them as autonomous and then have some insight into what they would (in that condition) consider appropriate? Or is the difference that we are making their medical decisions in order to, not restore, but bring about future autonomy? And with any of these approaches, how might we confirm that we had indeed guessed right, when it came to what the same subject, with autonomy, would fine appropriate?

In the literature that analyses nonconsensual care for the mentally ill, there is a "thank you" theory that has been proposed to justify nonconsensual treatment (Stone 1975). It offers some "back-up" justification to claims that we can determine what a person would want if autonomous. It takes the treatment at issue to be justified if the patient later comes to appreciate it. ${ }^{5}$ We can see how such an explanation might easily apply to children resisting routine dental cleanings. Yet I will explain why a form of "thank you" theory is inadequate to explaining why we can treat children non-consensually.

In general, I will aim to avoid the mistake that I see involved in a reliance on concepts like "experience" and "judgment" to establish legitimate consent. This mistake is to presume a normative take on life can be easily established and noncontroversial. I see this type of assumption as a matter of begging the question. It is also at odds with the very notion of autonomy under consideration. Any suggestion that consent be tied to a cognitive test that amounts to approval of one account of a flourishing life or perhaps the benefit of medical research, fails to acknowledge the possible approaches an autonomous person is said to be able to take to her decisionmaking. This means I would also like to reject the recent, and rather sophisticated,

\footnotetext{
4 Though this is not to say some lack of experience may not, of course, be brought up in court as a mitigating factor in criminal defense.

5 There have been questions raised as to how often mentally ill patients are grateful for the treatment they receive without giving consent, though I supposed this is not at issue here.
} 
suggestions, made by some bioethicists, that the age of "assent" could be determined to coincide with the onset of the ability to be altruistic (an approach that has been called "psychological") (Wender and Shah 2003).

What I hope to show instead is that we do not need to use understanding of chosen ethical concepts as a stand in for autonomous agency. Nor do we have to determine agency by some analysis of the choices agents make. We can rely on the research that that gives us some insight into how a child's agency actually functions. I would describe the approach I want to use as "developmental" in contrast to one that is "psychological." Development is already regularly referenced in regard to policies on these matters, I intend to extend this focus until we can describe the specific type of agency children have. Once we do that, we can look to what this type of agency means in terms of children's interests and our obligations in regard to these.

\section{The Moral Agency of Children}

John Locke described personhood as a forensic concept. He meant that we use "personhood" to decide who can be held responsible and who has rights. I will make use of research on cognition and agency in only a "forensic" manner, in order to develop a standard for who has agency and has the right to consent. The distinctions I make will be general and schematic, as is necessary to serve a "forensic" purpose, yet unlike current justifications, I want to mark out, in as systematic a way as possible, the differences between infants, young children, and teenagers' agency.

I also rely on other authors to put this research in an ethical context. Marya Schechtman's work on personal identity in The Constitution of Selves has provoked much continued thought on how we "create" our identity by forming an "autobiographical narrative" (a story of one's life) (Schechtman 1996, p. 93; Schechtman 2001, 2005, 2007). The "revelatory potential" of her view has been noted by prominent thinkers in bioethics, such as David DeGrazia, Francois Baylis, and others (Menzel 2010); yet what Schechtman proposes seems to clear up what our previous approaches had confused or obscured. ${ }^{6}$ A narrative account of self helps us to recognize what we take to constitute mature agency; an explanation of mature agency is invaluable to my attempted description of non-mature agency.

I am also making use of the work of Gary Varner (2012). His own aim is to reevaluate the moral status of animals, yet this has great relevance, as it connects levels of cognitive development to the experiential and ethical nature of harm. His attention to animal cognition reminds us that descriptors such as "rational" and "self-conscious" do not even distinguish between human and animal agency (let alone adult and children's agency). Without his arguments, I might be able

\footnotetext{
${ }^{6}$ Galen Strawson (2012) has recently suggested that the view may just be "trivially true," but I do not find this to be troubling in the least. Since I am not engaging in debates over strict personal identity or even over criteria for personhood, the non-controversial nature of the proposal seems an asset. That is, although narrative views of the self, like Schechtman's (1996) account, are used to debate standards for personhood as well as personal identity, I will only look to these accounts for what they contribute to our understanding of agency. There is less controversy in this.
} 
describe what makes a 4 year olds experience so different from a 14 year olds, but have no explanation for how this makes any moral difference.

The first stage in our moral development is that of "sentience." Pet animals are sentient. Infants are sentient. When it comes to humans, sentience is a precondition to developed agency. The merely sentient are not capable of accessing or forming accessible memories of having had experiences. Animal studies have revealed this rather thoroughly (Varner 2012, pp. 160-171). Before humans are 4 years old, we simply lack the brain structures that allow us to retain memories of experiences (Suddendorf and Busby 2005, pp. 114-115, 122). Infants lack what cognition researchers term "autonoetic consciousness."

Autonoetic consciousness can be explained by three of its features, each of which may be possessed to a matter of degree. These are: (1) episodic memory, (2) mirror self-recognition, and (3) the ability to recognize that others also have minds. Episodic memory is "remembering of personally experienced events" (Varner 2012, p. 184). A person with episodic memory is capable of retrieving features of a past experience, including what it was like to have been there for it. In order to understand this phenomenological requirement, Varner tells us to "think of a moviegoer who accurately recalls that she has seen a particular movie without having any consciousness memory of when or where, or of what the plot or images in the movie are like." (Varner 2012, p. 184) It seems to be at three and four that children acquire episodic memory.

Mirror self-recognition standardly emerges in children between 18 and 22 months of age. Mirror self-recognition demonstrates a level of self-awareness that many animals lack. Yet dolphins, elephants, apes, and some birds, like children, can recognize themselves in a mirror. Researchers have subjects respond to a surreptitiously placed and mirror-detectable mark. They see if subjects wipe the mark off of themselves when they see it in the mirror.

Theory of mind is the third aspect of autonoetic consciousness. To use "theory of mind" is to "interpret others' behaviors in light of their beliefs and desires" (Varner 2012 , p. 204). It is the indication that we have engaged in conscious thought about what is "inside the others' head" (Varner 2012, p. 204). It requires the agent's representation of someone else's mind. In animals, this ability is tested in many complex ways in order to rule out behaviorist explanations. There is less controversy concerning what blushing 5 year olds experience, as they can verbally explain what they take others to be thinking. These characteristics of autonoetic consciousness are characteristic of the agency of young children.

Standardly developing young children have "a capacity for self-awareness and an ability to plan for the future and have meaningful relationships with others" (Varner 2012 , p. 253). This particular stage of development, that of autonoetic consciousness, has important implications for the interests of agents. We turn to Varner's discussion of those momentarily. Yet this is not the end of our agential development.

Psychologist Dan McAdams has been testing a 'life story model' of identity that suggests that, as we develop, we begin to tell evolving and never-settled "stories" about ourselves, stories that reconstruct our past as well as involving hopes for the future (McAdams 2004). This ability is not said to be available to us until our teen 
years (McAdams 2003, p. 192; Varner 2012, p. 180). "Beginning in late adolescence and young adulthood," McAdams writes, "we construct integrative narratives of the self that selectively recall the past and wishfully anticipate the future to provide our lives with some semblance of unity, purpose, and identity" (McAdams 2006, p. 287). This means that in addition to the ability to recognize and relate to ourselves and others, which we have when we are younger, by our teen years we develop a notion of self that is partly constructed out of our descriptions and some articulated sense of our lives.

\section{Autobiographical Selves}

As mentioned, this idea, that we have "narrative" or "autobiographical" selves has been gaining currency in a number of fields, including bioethics (DeGrazia 2005). Psychologists have found the practice of telling stories is central to our practices and our well-being (see, e. g. Rubin 1986; Conway 1990; Fivush and Haden 2003). That we are in part a matter of the "traits, actions, and experiences" included in the various stories we tell about ourselves is now, as philosopher Galen Strawson (2012) has recently put it, a matter of "major consensus". 7

Schechtman's early contribution to this idea included the description of two constraints on how our narratives help determine who we are. One is the "reality constraint," which is just that our notion of self must have some tie (not a very reliable one and not necessarily a consistent one) to events that have actually happened. The second is the "articulation" constraint. This is a matter of being able to do more than just sense or intuit one's history. To truly create a narrative self in the way Schechtman describes, we must put our accounts of ourselves into linguistic form. Actually speaking is not necessary, we can have an implicit self-narrative. Yet we still "must be capable of responding to questions and challenges about one's implicit life story" (Varner 2012, p. 142). ${ }^{8}$ As Varner explains, "Without a complex representational system much like humans' natural languages, individuals could not be held subject to what Schechtman calls the articulation and reality constraints. For these require recognizing and responding to challenges to the coherence and content of one's chosen self-narrative, and that can only be done via a very complex system of public communication" (Varner 2012, p. 148).

\footnotetext{
7 Schechtman's proposal in her influential 1996 book was that "a person creates his identity by forming an autobiographical narrative-a story of his life... On this view a person's identity is constituted by the content of her self-narrative, and the traits, actions, and experiences included in it are, by virtue of that inclusion, hers" (Schechtman 1996, pp. 93-94). She now offers a different account, a "person-life view," and a forthcoming book promises to explain it at length. She writes that "the basic strategy of PLV is to think of a person in terms of a certain type of developmental trajectory. "(2010, p. 279) Yet it is not like her earlier view in that there is a greater emphasis on relationships helping to constitute a person. For our purposes, it is the developmental account of agency (a lesser standard than "personality identity" or "personhood") that continues to matter.

8 "If one did not recognize the legitimacy of such questions and challenges and at least generally try to answer them, one would not be thinking of oneself as a person in the sense of an individual whole life unfolds according to the logic of narrative" (Varner, 142).
} 
Varner contributes what we might think of as a third, mutually reinforcing, requirement for possessing a narrative self. He emphasizes that it is not linguistic ability alone that enables a narrative sense of self. The appreciation of several complex concepts is necessary to representing one's own developed agency. Varner details the research that shows that even the complex vocalizations of cetaceans and elephants do not have a structure complex enough-one including tense-one including the notions of self, birth, death, and personality - to support a narrative sense of self.

In this way, Varner offers us a means of distinguishing between the agency of very young children, older children, adolescents and adults (or those who ought to be counted as such). Fully developed agency involves a narrative sense of self, and if an agent demonstrates the ability to describe one's life in verbal terms (literally speaking not being necessary), with reference to some crucial concepts, she has sufficiently demonstrated mature agency. A teenager, then, who can explain what his religious faith means to him and the consequences of not accepting a blood transfusion, may be recognized as having the same status as an adult agent. Again, this ability is not a matter of having an accurate story or realistic hopes for one's future. It is also not related to any appreciation of the values we want to honor in medicine. The approach does not beg the question as to what counts as autonomy in that way.

With this I hope we have satisfied one of two desiderata I set out: that we offer an explanation as to what makes the difference in the reasoning and experience of a 4 and a 14 year old. There are some situations, of course, that render adults unable to meaningfully consent to treatment. These should be capable of being explained with the notion of narrative self-constitution being necessary to full agency, as well. Persons in manic states, if they cannot access a narrative account about themselves that meets the "reality" or "articulation" constraint will be in a situation more like that of non-adults. If a severely cognitively disabled person cannot access a narrative account of self, then we may appoint a guardian or grant a conservatorship to their caretaker. On the other hand, an addict, even if she can be shown to have experienced the brain changes we now associate with addiction, may easily meet all three constraints (reality, articulation, and Varner's focus on particular concepts). Thus, using this approach, we would still seek consent for treatment from addicts.

Let us move on to see if we can meet a second desiderata: that a developmental account of agency explain why we respect foolish reasoning on behalf of adults, but not on behalf of minors, with the exception of minors who are married, homeless, mentally ill or drug addicted.

\section{The Impact of Agency on Interests}

Those with narrative selves are said to be made capable of being able to judge what is in an agent's best interest as a whole. Varner and Schechtman refer to this as the "Lives-As-A-Whole" feature of mature agency, and lay out the concept thusly. There is, Schechtman begins, 
a certain primitive concern we have for the character of any state that will be ours at all-we care whether it will be pleasurable or painful. Furthermore, we have a special concern for our desires and goals and the beliefs they express. The goals and desires that occurs in a person's history are not, however, all equally his, and so a person should not be equally concerned with the fulfillment of every desire or goal that occurs in his history. For a person to have self-interested concern for the fulfillment of a desire, that desire must, to be sure, at least be part of his history. Among those goals which fulfill this minimal requirement, however, the degree to which any particular goal is attributable to a person is at least part of what determines the degree to which he should be concerned about it (1996, p. 85; Varner 2012, p. 174).

What is crucial for us to recognize is that, with agents who have narrative senses of self, we cannot predict which way any value input will go. This is part and parcel of why the recognition of autonomy is the recognition that autonomous choices must not meet standards that we impose from the outside through some measure of benefits and harms. Varner explains that "the ability to tell and understand stories can augment the value of a person's life in both positive and negative ways, and it is possible to harm of benefit persons through kinds of treatment that would be indifferent in terms of the their effects on (those lacking narrative selves) lives" (Varner 2012, p. 167).

We are looking to establish the following to claims about the lives of mature agents: harms can come to exist or be amplified when done to a person, due to her narrative sense of self. We cannot predict how a narrative sense of self might "transform" an event into a harm or a benefit. I would like to refer to the types of interests that can be transformed through mature agency as "transformable interests." I want to highlight what these are and then turn to why I think we should understand non-mature agents as lacking access to these.

\section{Transformable Interests}

Having a right to one's body is not the same as recognizing deep interests in the protection of your body. It is not even the same as recognizing interests in having your agency (concerning your body) respected. When we grant rights to one's body, we grant the scope that allows for its harm. Narrative self-constitution, an aspect of mature agency, can transform chosen harm into a benefit. Without it, we would just see harm. We would see many of the choices mature agents take to simply be a matter of harm. We do not tattoo children, for example. Yet, when a mature agent makes the choice, even if we have the same perspective on the harm being done, it is of course transformed by the ability of an agent to incorporate a tattoo into her story. Resisting medical treatment would be similar, it can be transformed into a benefit when a person can tell a story about why she would rather take on risks many of us would not deem prudent. A young teen could of course "tell a story" about this, but not in a manner that meets the criteria of mature agency.

Once you have a biographical sense of self, you can confer authority on medical procedures you have consented to because we expect that you are fitting the 
procedure into your own narrative. This means you have endorsed it as worth including in your life. This is a method of justification. Finally, any pre-conditions on one's reasoning, such as it being "sensible" or "valid," can be understood to be bypassed by our confidence that a person with a biographical sense of self may make decisions in accordance with a life plan, or sense of life, that does not suggest to us sensibility or validity. This, though, works as the excuse for foolish decisions. Again, great harms can be turned, by a person developing a life story, into great benefits. We respect this when we respect autonomy. ${ }^{9}$

\section{Non-transformable Interests}

Children do not have the ability to think of "their lives as a whole." This means the ability to transform a seeming harm into a benefit is not available to them. Yet they are also unlike the merely sentient, in that they will experience pain along with selfconsciousness, the impact of memory, and the interruption of a self-directed plan. A young child may experience and then retain feelings of humiliation, for example, on the basis of some painful treatment that caught her off guard. We do not expect harms done to infants to involve humiliation because they do not have the autonoetic consciousness necessary to it. Male infant circumcision may work as an example. Harm is amplified when the agent experiencing the pain is capable of doing so along various dimensions, through time and in relationship to other (perhaps once trusted) persons. Though one could argue that the physical effect might be the same, or the risks similar, circumcising a 4 year old would involve an additional type of harm than that done to an infant.

I want to suggest that prior to having mature agency, many of our interests are "non-transformable." They cannot depend upon the use we make of them in our own self-construction. To make a case for how useful the category of "nontransformable" interests is, I would like to argue two things. One is that respect for "non-transformable interests" may not only limit the powers of parents but might require drastic interventions at the behest of parents. In other words, this approach to minors does not lead to the same preference for inaction that we might rightly take in response to an autonomous agents' inability to give consent. The other is that we have obligations to non-mature agents due, in part, to their non-transformable interests.

\section{Obligations to Children}

Autonomy, Varner explains, "is achieved when (we) succeed in living out (our) chosen self-narratives, and (our) chosen self-narratives determine, to a significant

\footnotetext{
9 Strawson (2012) is very critical of any account of narrative self-constitution that is not trivially true. He writes "For to identify oneself with one's narrative of oneself, to take one's narrative of oneself to constitute one's identity, is likely to be a desperately reductive (if not murderous) act-and for several reasons. Not only because we live beyond any tale that we happen to enact, but also because there are many respects in which we're not very good at knowing much about ourselves, or about why we do what we do."
} 
degree, what is in (our) best interests "all things considered." He continues, these "facts about persons gives their lives special moral significance" (Varner 2012, p. 174). We can sometimes assume that being autonomous means a person deserves more from us. Varner makes it sound that way in this quotation. But we can cash his view out in this way: we do grant more to autonomous adults in the sense that we grant them legal rights, including that of being able to consent to medical treatment. This, however, is not the same as being more obligated in terms of the particular interests that arise other than these legal protections. When it comes to children, and those without mature agency, we think the nature of their interests, the nontransformable nature of interests such as avoiding fear and pain, ensure our obligations. As readily as we can recognize them, we can see the value in providing non-mature agents such regularly needed benefits. Common sense recognizes that to leave a child in distress is a particularly inexcusable thing, and the reasoning is the same.

There is a fear that any effort to classify standard human development as normatively significant will become a way to reinforce a bias towards the interests of those who have experienced the development. ${ }^{10}$ Yet non-mature agents are not to be treated worse. Varner argues the same in regard to animals with autonoetic consciousness. It is reversed: we have obligations to the interests of those with autonoetic consciousness that differ. We are morally required to provide satisfaction of the more basic and easily identifiable interests of agents that lack self-narratives.

\section{Applications}

\section{Growth Attenuation}

One implication of this approach is that concepts that previously stood in for what explained why we do not seek consent for children will be replaced with alternative explanations. Interventions that are often rejected as too extreme can come to be seen as more acceptable, if we use this developmental account of agency. A child that can be reliably determined to be incapable of reaching autonoetic consciousness at any point in her development should not, I want to suggest, be treated as if her interests can be represented by an "open future." This will assume a future in which she develops an agency capable of "transforming" her interests. A hands-off approach might seem best if we rely on the notion of an "open future," but this might be to disregard some non-transformable interests.

Bioethics can do a disservice to parents of the profoundly disabled in a number of ways. One is with the expectation that these parents regard their children's interests

\footnotetext{
${ }^{10}$ National Center for Disabilities representative Jeff Rosen, in response to prosecution of parent and caretaker for the murder of a disabled child: "To do otherwise sends the message that the short life of Alex Spourdalakis was worth less than the lives of other children and reinforces the notion that killing one's child if they are disabled, while regrettable, is understandable." He continued, "This way of thinking should not go unchallenged, and the fervor with which we investigate and prosecute the perpetrators of crimes against people with disabilities should not be diminished." Accessed online Sept. 8, 2013: http://www.ncd.gov/newsroom/06192013.
} 
as those that may become transformed through the later development of agency. If there can be no such anticipated later development, wholly different standards must be applied to the child's interests. If a family and their physician is certain that sexual organs, for example, ovaries, might be removed and that future pain thereby be allayed, this can be regarded as an appropriate response to the non-transformable interests of person who will always remain an immature agent (Pilkington and McVeigh 2013). Charges of violation of dignity or thwarting an open future ought to be predicated on the actual harms and benefits that can come to the child in question. Yet this developmental account helps us to recognize that extraordinary interventions are sometimes justified (growth attenuation on the severely disabled) and sometimes unjustified (sex assignment surgery).

\section{Sexual Reassignment Surgery}

"Assigning" a child a sex when born with ambiguous genitalia can be seen to cause horrific distress for some children as they mature. Can our account explain why in terms of transformable interests? It can. Unlike dental care or vaccinations, sexual reassignment surgery does not promote an individual's health, a non-transformable good, as either sex can be equally healthy. Instead, it determines a biological feature that is normally the result of natural processes. One's sexuality is, by its nature, made up of transformable interests and related to, though not determined by, one's sex. It requires agency for activation. This means that no one other than the developed agent would have insight into the use a person might make of her sexual agency. The nature of the interest in sexual agency requires activation by a mature agent. Some procedures, ones that maintain the viability of future reproduction, for example, reflect such general interests that the role of later agency is less relevant. But sexual reassignment surgery seems to require confidence in a child's future use of her sexuality. This aspect of sexuality involves transformable interests. This suggests that a hand's off approach is the best way to respect the existent nontransformable interests of an infant with ambiguous genitalia. Any surgery should be deferred until the individual has developed a narrative sense of self that incorporates a sexual identity.

\section{Homelessness, Sexual Health, Mental Illness, and Addiction}

This developmental account can also support current exceptions for minors who are homeless, or in need of care for sexual health, mental illness, or addiction. As would generally be the case, if these minors can explain themselves in terms of the concepts crucial to maintaining a narrative sense of self, we ought to allow them to render consent. But what is at stake in these situations are interests that, through their very nature, require us to think of them as transformable. Sexual health means risks are taken for a benefit that is sexual or reproductive. Homelessness transforms the situation of a minor in such a way that what is generally taken to be of benefit may not manage to achieve its target. Mental illness and addiction may involve a minor asking for interventions that would seem harmful to a person without these afflictions. Interventions request for mental illness or addiction are not the same as 
getting one's tooth drilled. Drilling might also bring about harm (pain or distress), but the rationale is that greater harm will be avoided thereby. The benefits of addiction treatment or mental illness are more nebulous. Because the choices the individuals in these situations face are not clear-cut and affect more than simply what promotes general health, what they are consenting to cannot be considered a non-transformable good. It can only be valued in the context of their autobiographical senses of self. This approach reminds us that very adult-sized life issues can certainly become part of a young person's life. To reckon with them, minors are put in the position of having to think about their "lives as a whole." We see how minors in these unusual situations can be expected to consent to medical treatment. The decisions they are making, in regard to their medical treatment, are ones we usually associate with the lives of mature agents, ones we assume operate with autobiographical senses of self.

\section{Conclusion}

Certainly this is only an initial sketch of the ways in which a developmental account of agency might provide useful to the issue of children and medical consent. It is easy to presume that various normative take on life can supplement our commitment to autonomy. Honoring autonomy, after all, depends on a very large range of philosophical support. Yet we should be careful, I want to conclude, before we take other values to apply to the decisions of agents. Dignity and an open future do not seem like concepts anyone would contest; that is, until either is used to explain to you why you cannot seek treatment for your child. Without a developmental account, like the one I've proposed here, we might have thought that consent, as it is meant to be used in an ethical context, is easy enough to associate with some account of a flourishing life or perhaps the benefit of medical research. But again, this is to beg the question and would seem to pose a challenge to adult autonomy. I hope to have presented a more straightforward way to think about why and when we must seek consent from children for their medical treatment. The explanations cannot stray from the nature of agency, our very experience of life itself.

\section{References}

American Academy of Pediatrics Committee on Bioethics. (1995). Informed consent, parental permission, and assent in pediatric practice. Pediatrics, 95, 314-317.

Conway, M. (1990). Autobiographical memory: An introduction. Maidenhead, England: Open University Press.

DeGrazia, D. (2005). Human identity and bioethics. Cambridge, MA: Cambridge University Press.

Fivush, R., \& Haden, C. (2003). Autobiographical memory and the construction of a narrative self. Mahwah, NJ: Lawrence Erlbaum Associates.

Hartman, R. G. (2002). Coming of age: Devising legislation for adolescent medical decision-making. American Journal of Law \& Medicine, 28, 409-453.

Lee, K. J., Havens, P., Sato, T., Hoffman, G., \& Leuthner, S. (2006). Assent for treatment: Clinician knowledge, attitudes, and practice. Pediatrics, 118(2), 723-730. 
Mature Minor Doctrine, TN. Retrieved October 14, 2013 from www.health.state.tn.us/STD/PDFs/ Mature\%20Minor\%20Doctrine.pdf.

McAdams, D. (2003). Identity and the life story. In: R. Fivush \& C. Haden.

McAdams, D. (2004). The redemptive self: Narrative identity in America today. In D. R. Beike, J. M. Lampien, \& D. A. Behrend (Eds.), The self and memory (pp. 95-115). New York: Psychology Press.

McAdams, D. (2006). The redemptive self: Stories Americans live by. Oxford: Oxford University Press.

Menzel, P. T. (2010). The significance for bioethics of Marya Schechtman's the constitution of selves and its "Narrative Self-Constitution" view of personal identity. APA Newsletters, 9(2), 36. (Special section).

Neiman Reports. (2013). Revealing how dentists profit by abusing children. Retrieved September 6, 2013 from http://www.nieman.harvard.edu/reports/article/100963/Revealing-How-Dentists-Profit-ByAbusing-Children.aspx.

Pilkington, E., \& McVeigh, K. (2013). Ashley treatment on the rise amid concerns from disability rights groups, Retrieved September 13, 2013 http://www.theguardian.com/society/2012/mar/15/ashleytreatment-rise-amid-concerns?newsfeed=true.

Rubin, D. (1986). Autobiographical memory. Cambridge, MA: Cambridge University Press.

Schechtman, M. (1996). The constitution of selves. Ithaca: Cornell University Press. (Reissued 2007).

Schechtman, M. (2001). Empathic access: The missing ingredient in personal identity. Philosophical Explorations, 4, 95-111.

Schechtman, M. (2005). Self-expression and self-control. In G. Strawson (Ed.), The self?. Oxford: Blackwell.

Schechtman, M. (2007). Staying alive: personal continuation and a life worth living. In K. Atkins \& C. McKenzie (Eds.), Practical identity and narrative agency (pp. 31-55). New York: Routledge.

Schloendorff, V. (1914). Society of New York Hospital. 105 N.E. 92 (N.Y. 1914).

Stone, A. A. (1975). Mental health and law: A system in transition. Rockville, MD: NIMH Center for Studies of Crime and Delinquency.

Strawson, G. (2012). We live beyond any tale that we happen to enact. Harvard Review of Philosophy, 18, 73-90.

Suddendorf, T., \& Busby, J. (2005). Making decisions with the future in mind: developmental and comparative identification of mental time travel. Learn. Motivation, 36, 110-125.

The President and Directors of Georgetown College, Inc. (1964). 331 F.2d 1000 (D.C.Cir.), cert. denied, 377 U.S. 978, 84 S.Ct. 1883, 12 L.Ed.2d 746 (D.C.Cir.1964).

Varner, G. (2012). Personhood, ethics, and animal cognition: Situating animals in hare's two level utilitarianism. Oxford: Oxford University Press.

Wender, D., \& Shah, S. (2003). Should children decide whether they are enrolled in nonbeneficial research? The American Journal of Bioethics, 3(4), 1-7. 